\title{
Evaluation of an Injectable, Photopolymerizable, and Three- Dimensional Scaffold Based on Methacrylate-Endcapped Poly(D,L-Lactide-co-e-Caprolactone) Combined with Autologous Mesenchymal Stem Cells in a Goat Tibial Unicortical Defect Model
}

\author{
Geert Vertenten, D.V.M., ${ }^{1}$ Evi Lippens, M.Sc., ${ }^{2}$ Jordi Gironès, Ph.D., ${ }^{3}$ Tomasz Gorski, Ph.D., ${ }^{3}$ \\ Heidi Declercq, Ph.D., ${ }^{2}$ Jimmy Saunders, D.V.M., Ph.D., Dip.ECVDI, ${ }^{4}$ \\ Wim Van den Broeck, D.V.M., M.Sc., Ph.D., ${ }^{5}$ Koen Chiers, D.V.M., Ph.D., Dip.ECVP, Dip.ECPHM, ${ }^{6}$ \\ Luc Duchateau, Ph.D., ${ }^{7}$ Etiene Schacht, Ph.D., ${ }^{3}$ Maria Cornelissen, Ph.D., ${ }^{2}$ \\ Frank Gasthuys, D.V.M., Ph.D., Dip.ECVAA, ${ }^{1}$ and Lieven Vlaminck, D.V.M., Ph.D., Dip.ECVS ${ }^{1}$
}

\begin{abstract}
An in situ crosslinkable, biodegradable, methacrylate-endcapped poly(D,L-lactide-co-e-caprolactone) in which crosslinkage is achieved by photoinitiators was developed for bone tissue regeneration. Different combinations of the polymer with bone marrow-derived mesenchymal stem cells (BMSCs) and $\alpha$-tricalcium phosphate $(\alpha-\mathrm{TCP})$ were tested in a unicortical tibial defect model in eight goats. The polymers were randomly applied in one of three defects $(6.0 \mathrm{~mm}$ diameter) using a fourth unfilled defect as control. Biocompatibility and bone-healing characteristics were evaluated by serial radiographies, histology, histomorphometry, and immunohistochemistry. The results demonstrated cell survival and proliferation in the polymer-substituted bone defects. The addition of $\alpha$-TCP was associated with less expansion and growth of the BMSCs than other polymer composites.
\end{abstract}

\section{Introduction}

L ARGE BONE DEFECTS in humans and animals generally do not heal spontaneously and require, in most cases, a specific surgical intervention for the reconstruction of the defect. One of the possibilities is the use of an autologous trabecular graft. The inherent drawback of an autologous graft, however, is that the grafts have to be harvested from another place in the body, resulting in donor-site morbidity. ${ }^{1}$ A possible alternative is the use of allogenic bone collected from a donor of the same species. These grafts were proven to have a lower osteogenic capacity, a higher resorption rate, a larger immunogenic response, and less extensive revascularization than autologous grafts. Further, there are justified concerns about possible viral contamination of the graft material, including transmission of live virus to the recipient. ${ }^{2}$
Bone regeneration using tissue engineering techniques has emerged as an alternative approach in the treatment of malfunctioning or depleted bone. In this approach, a biomaterial scaffold can be implanted in the bone defect. This scaffold serves as an adhesive substrate for seeded cells and assures a sufficient physical support to guide the formation of the new bone-related extracellular matrix (ECM). The use of autologous cell sources has received widespread attention because of the potential benefits in the tissue engineering process. $^{3-5}$

The design criteria for polymeric scaffolds for bone tissue support include a high porosity, structural integrity, and degradability at a rate commensurate with the production of new ECM by cells seeded on the scaffold. A highly porous scaffold is desirable to allow uniform cell migration throughout the material and to optimize transport to and from

\footnotetext{
${ }^{1}$ Department of Surgery and Anaesthesiology of Domestic Animals, Faculty of Veterinary Medicine, Ghent University, Merelbeke, Belgium.

${ }^{2}$ Department of Human Anatomy, Embryology, Histology, and Medical Physics, Faculty of Medicine and Health Sciences, Ghent University, Ghent, Belgium.

${ }^{3}$ Polymer Material Research Group, Faculty of Sciences, Ghent University, Ghent, Belgium.

${ }^{4}$ Department of Medical Imaging of Domestic Animals, Faculty of Veterinary Medicine, Ghent University, Merelbeke, Belgium.

${ }^{5}$ Department of Morphology, Faculty of Veterinary Medicine, Ghent University, Merelbeke, Belgium.

${ }^{6}$ Department of Pathology, Bacteriology, and Poultry Diseases, Faculty of Veterinary Medicine, Ghent University, Merelbeke, Belgium.

${ }^{7}$ Department of Physiology and Biometrics, Faculty of Veterinary Medicine, Ghent University Merelbeke, Belgium.
} 
implanted cells. Pore size and interconnectivity play a major role in tissue ingrowth, creating an internal surface area available for cell attachment, spreading, and expansion. The mechanical properties of the scaffold are also of major importance, especially with respect to hard tissues such as bone, to transmit mechanical force and manage mineralization requirements. ${ }^{6}$

We previously reported that the in situ crosslinkable methacrylate-endcapped porous bone scaffold composed of D,L-lactide, $\varepsilon$-caprolactone, 1,6-hexanediol, and poly (orthoesters) could be used as a substrate for bone tissue engineering. ${ }^{7}$ This polymer showed excellent biocompatibility and moderate osteoconductive properties in vivo. The addition of $\alpha$-tricalcium phosphate $(\alpha-\mathrm{TCP})$ increased the latter characteristics. ${ }^{7}$ In other parallel experimental work, mouse embryonic stem cells were cultivated on commercially available biodegradable macroporous microcarriers, and osteogenic differentiation was initiated in an adapted medium for a period of 2 weeks. Encapsulation of the cell-loaded microcarriers in the experimental scaffold, using either triacetin or hydroxyethylmethacrylate (HEMA), as solvent and with or without gelatine, as porogen, resulted in a homogeneous distribution of the microcarriers in the polymer. However, viability of the cells was estimated by transmission electronic microscopy to be optimal when gelatine was omitted, and triacetin was added instead of HEMA. ${ }^{8}$

The objective of the present study was to evaluate the effect of mesenchymal stem cells loaded on microcarriers in combination with the crosslinkable methacrylate-endcapped porous polymer scaffold including $\alpha$-TCP on bone regeneration in a unicortical tibial defect experimental design in a goat model. We firstly hypothesized that the implanted cells would easily survive and proliferate, and would demonstrate bone-forming characteristics inside the polymer scaffold. We secondly anticipated an improvement in bone healing characteristics of the treated cortical defects compared to earlier reported results concerning a comparable experiment without the use of stem cells. ${ }^{7}$

\section{Materials and Methods}

The study was approved by the Ethics Committee of the Faculty of Veterinary Medicine, Ghent University (EC 2006/097). Eight adult female goats with a mean age of $46.3 \pm 22.9$ months and a mean body weight of $54.1 \pm 7.5 \mathrm{~kg}$ were used. The goats were housed in groups (groups of four in boxes of $16 \mathrm{~m}^{2}$ ) and had free access to food and water. All surgical procedures were performed under general anesthesia respecting all aspects of the well-being of the animals (including starvation before surgery, as well as antibiotics and analgesics before, during, and after surgery). ${ }^{7}$

\section{Isolation and culture of bone marrow-derived cells}

Bone marrow (BM) was aspirated by a Jamshidi needle (11 gauge, $10 \mathrm{~cm}$; DMS, Hampshire, United Kingdom) under sterile conditions from the iliac crest of the anesthetized goats. The BM was collected in a $10 \mathrm{~mL}$ lithium heparin tube (Venoject, Leuven, Belgium) in which $1 \mathrm{~mL}$ of ACD-A anticoagulant (Anticoagulant Citrate Dextrose Solution Formula A; Baxter, Brussels, Belgium) was added. The needle was abundantly flushed with ACD-A anticoagulant and lithium heparin before the aspiration of the BM. After removal of blood clots, the BM was thoroughly washed with Minimum Essential Medium (MEM)- $\alpha$ medium containing $10 \mathrm{vol} \%$ fetal bovine serum (FBS), $0.5 \mathrm{vol} \%$ penicillin-streptomycin, and $1 \mathrm{vol} \%$ Funigizone Amphotericin B (Invitrogen, Merelbeke, Belgium), and centrifuged (10 $\mathrm{min}, 1000 \mathrm{rpm})$. The cell pellet was resuspended in osteogenic differentiation medium, that is, MEM- $\alpha$ medium supplemented with 10 vol\% FBS, $0.5 \mathrm{vol} \%$ penicillin-streptomycin, 1 vol\% Fungizone Amphotericin B, $100 \mu \mathrm{M}$ L-ascorbic acid 2-phosphate (Sigma-Aldrich NV/SA, Bornem, Belgium), and $10 \mathrm{nM}$ dexamethasone (Sigma-Aldrich NV/SA), and seeded in five T75 tissue culture dishes. The culture dishes were placed in a humidified incubator $\left(37^{\circ} \mathrm{C}, 5 \% \mathrm{CO}_{2} / 95 \%\right.$ air $)$, and the medium was renewed after 2 days, leading to the removal of the nonadherent cells (mainly hematopoietic cells). Stromal cells were kept in culture for 2 weeks (renewal of the medium twice a week) until they reached confluence. Afterward trypsinized, the cells were brought in suspension, stained with trypan blue, and counted in a Bürcker cell chamber. CultiSpher-S microcarriers (diameter 130-380 $\mu \mathrm{m}$ ) (Percell Biolytica AB, Åstorp, Sweden) were prepared and sterilized according to the manufacturer's instruction. About $0.09 \mathrm{~g}$ hydrated carriers were divided over 5 wells of a 12-well suspension plate in osteogenic medium. Approximately 400,000 cells were added to each well, depending on the amount of harvested cells. Cells were allowed to adhere under static conditions for $48 \mathrm{~h}$. Afterward, the cell-carrier constructs were carefully transferred to a dynamic culture system (stirring speed $55 \mathrm{rpm}$ ) as has been described by Declercq et al. ${ }^{9}$ The constructs were cultured for an additional 2-3 weeks in osteogenic differentiation medium, with the addition of $\beta$-glycerophosphate after 1-week colonization at $37^{\circ} \mathrm{C}\left(5 \% \mathrm{CO}_{2}\right)$. Before implantation, cell colonization on the carriers was evaluated by 3-(4,5-dimethylthiazol-2-yl)-5(3-carboxymethoxyphenyl)-2-(4-sulfophenyl)-2H-tetrazolium salt (MTS) analysis (100 $\mu \mathrm{L}$ MTS solution added to $100 \mu \mathrm{L}$ CultiSpher carriers in $500 \mu \mathrm{L}$ phenol-red-free medium). After 4-h incubation in the dark at $37^{\circ} \mathrm{C}$, the reduction of the tetrazolium salt into formazan in living cells was determined spectrophotometrically by measuring the absorbance of the colored formazan at a wavelength of $480 \mathrm{~nm}$. The cell-loaded constructs were mixed with the polymer and implanted in the tibial defects.

\section{Preparation of scaffolds}

The synthesis and characterization of the methacrylateendcapped polymers (D,L-lactide-co-caprolactone) have been described in depth earlier. ${ }^{7-9}$ Composition of the scaffolds was selected based on the results previously reported. ${ }^{8,9}$ No extra porogen was included in the composition of the scaffolds. Preceding experiments showed that porosity could be induced by the leaching of the plastizer and as a result of the degradation of the polyester and the CultiSpher microcarrier particles. Further, during the mixing of the viscous crosslinkable polyester and the cell-seeded microcarriers, air bubbles were trapped and contributed as macroporous pockets. In vitro experiments with cells grown on microcarriers and immobilized in the crosslinkable polyester proved to maintain an acceptable viability.

Three different preparations of the scaffold were used in the present study. Composite no. 1 consisted of pure 
methacrylate-endcapped polymer with a triacetin solution containing the photoinitiators as plasticizers. In composite no. 2, this mixture was supplemented with microcarriers loaded with autologous mesenchymal stem cells differentiated in the osteogenic lineage. In composite no. $3,30 \% \mathrm{w} / \mathrm{w}$ $\alpha-\mathrm{TCP}$ was further added to the polymer-triacetin-microcarrier mixture.

All polymers were sterilized by ethylene oxide for $12 \mathrm{~h}$ at $37^{\circ} \mathrm{C}$ and subsequently aerated for $48 \mathrm{~h}$. The cell-loaded CultiSpher-S carriers were thoroughly rinsed with physiological solution and shortly dehydrated by pipetting the constructs on filter paper. Two hundred and fifty microliters of these carriers were added to the catalyst/triacetin/ polymer $/(\alpha-\mathrm{TCP})$ paste and carefully mixed.

\section{Surgical procedure}

The surgery was performed as described earlier. ${ }^{7}$ Briefly, four noncritical-sized defects $(6.0 \mathrm{~mm}$ diameter) were drilled in the medial diaphyseal cortex of each tibia using a trephine burr (3I; Implant Innovations, Copenhagen, Denmark). In each leg, the three composites were randomly assigned to a hole, whereas the fourth hole was left empty to serve as a control. Each composite was first placed on the borders and bottom of the defect, and photopolymerized for $40 \mathrm{~s}$ $\left(500 \mathrm{~mW} / \mathrm{cm}^{2}\right.$ blue light, Visible Light Curing Unit ${ }^{\mathrm{TM}}$; $3 \mathrm{M}$ Unitek, Diegem, Belgium). Afterward, the remaining defect was further filled with a second layer of additional polymer before the standard wound closure.

During the study period, goats were daily evaluated for healing of the surgical site and development of complications related to the surgical intervention.

At, respectively, 2, 4, 8, and 12 weeks after surgery, two goats were euthanized and tibial defects were harvested for histological and immunohistochemical analysis of bone healing.

\section{Clinical and radiographic follow-up}

During the complete study period, goats were daily clinically evaluated for healing of the surgical site and development of possible complications related to the surgical intervention.

Immediately after surgery, standardized craniocaudal and mediolateral digital radiographs (Digivex $4015 \mathrm{~kW}$ highfrequency generator; Medex Loncin S.A., Loncin, Belgium) of each tibia were taken. At 2 weeks' interval, healing of the tibial defects was radiographically evaluated in each goat until the time of euthanasia, when further histological and immunohistochemical analysis of the bone defects was performed.

All radiographs were blindly evaluated for defect radiographic density, periosteal reaction, and soft tissue reaction using the criteria described by Dorea et al. ${ }^{10}$ Gray-scale densities at the level of the bone defects were further objectively evaluated using a standard imaging software packet (Image J 1.34S; National Institutes of Health, Bethesda, Maryland).

\section{Histological and immunohistochemical analysis}

After euthanasia, the different bone defect sites were harvested from the tibias. Because it was one of the aims to perform a von Kossa staining on the histological sections, undemineralized samples were embedded in destabilized Technovit 9100 New (Heraeus Kulzer, Wehrheim, Germany) as described earlier. ${ }^{7}$ Four-micrometer sections were cut with a heavy duty microtome (SM2500; Leica Microsystems, Wetzlar, Germany), stretched with $70 \%$ ethanol on a slide, and dried for $12 \mathrm{~h}$ at $60^{\circ} \mathrm{C}$.

The sections were stained with hematoxylin and eosin (H\&E), von Kossa, and Toluidine blue stain. All samples were qualitatively evaluated using a standard light microscope by the same investigator blinded to treatment. Evaluation criteria included the tissue type, presence of residual graft material within the defect, the quality of bone healing, and the presence of inflammatory reaction.

Histomorphometric analysis was performed with a $2 x$ magnification (Olympus BX61 Microscope; Olympus Soft Imaging Solutions $\mathrm{GmbH}$, Münster, Germany) on the von Kossa-stained sections using a specific software program (Analysis 5.0; Olympus Soft Imaging Solutions GMbH). The surface area of von Kossa-positive (black-brown coloration representing calcified tissue), von Kossa-negative (violet coloration representing connective tissue), and colorless (representing polymer and artifacts) stained materials were measured and expressed as a percentage of the total defect area.

All sections were stained immunohistochemically for cluster of differentiation 3 (CD3) (lymphocytes), MAC387 (macrophages), vimentin (mesenchymal tissue), and osteocalcin, ${ }^{11}$ and evaluated for the presence and localization of positive staining. Before immunohistochemical staining, sections were deacrylized. Antigen retrieval was performed using proteinase K (Dako, Heverlee, Belgium). The sections were rinsed with distilled water and phosphate-buffered saline (PBS). Endogenous peroxidase was quenched by incubating the sections in a $3 \%$ hydrogen peroxide solution in methanol. This was followed by rinsing in distilled water and PBS. The sections were preincubated in bovine serum albumin and rinsed with PBS. Consequently, immunohistochemical staining was performed using the primary antibody. The sections were rinsed with PBS and incubated with biotinylated goat anti-mouse for the monoclonal primary antibodies and biotinylated goat anti-rabbit for the polyclonal antibodies. Afterward, the sections were rinsed and incubated with avidin-biotin complex-horseradish peroxidase (Dako). The samples were rinsed with PBS and incubated in 3,3'-diaminobenzedine (Sigma, Bornem, Belgium) and finally rinsed with distilled water. Counterstaining was done by immersing the sections in hematoxylin, tap water, and distilled water. Finally, the sections were dehydrated and covered. The described protocol was used for all immunostainings except for CD3, where the PBS was changed for tris-buffered saline. ${ }^{11}$

\section{Statistical analysis}

Relationships between the age of the goats, and the volume of BM and retrieved cells after culturing were studied by the Pearson's correlation coefficient.

The radiographic scores for defect radiographic density, periosteal reaction, and soft tissue reaction were compared between the three composites, and the control defect by the Friedman test with tibia and time as block factor at the 5\% global significance level. The three composites and the control 
Table 1. Quantitative Values of the Bone Marrow Harvested from the Iliac Arch in Eight Goats

\begin{tabular}{lcccccccc}
\hline & Goat 1 & Goat 2 & Goat 3 & Goat 4 & Goat 5 & Goat 6 & Goat 7 & Goat 8 \\
\hline Age (months) & 34 & 91 & 32 & 35 & 35 & 21 & 60 \\
Vol BM (mL) & 6 & 11 & 8 & 9 & 8 & 17 & 21 & 12 \\
\# Cells 14 d culture & $8.28 \times 10^{6}$ & $3.66 \times 10^{6}$ & $2.00 \times 10^{6}$ & $2.75 \times 10^{6}$ & $1.48 \times 10^{6}$ & $6.00 \times 10^{6}$ & $2.36 \times 10^{6}$ & $6.00 \times 10^{6}$ \\
\# Cells on microcarriers & $6.00 \times 10^{6}$ & $3.66 \times 10^{6}$ & $2.00 \times 10^{6}$ & $2.75 \times 10^{6}$ & $1.48 \times 10^{6}$ & $6.00 \times 10^{6}$ & $2.36 \times 10^{6}$ & $6.00 \times 10^{6}$ \\
\# Carriers (g) & 0.27 & 0.18 & 0.126 & 0.18 & 0.09 & 0.27 & 0.144 \\
\# Cells/0.09 g carrier & $2.00 \times 10^{6}$ & $1.83 \times 10^{6}$ & $1.42 \times 10^{6}$ & $1.38 \times 10^{6}$ & $1.48 \times 10^{6}$ & $2.00 \times 10^{6}$ & $1.48 \times 10^{6}$ & $2.00 \times 10^{6}$ \\
Period on carriers (days) & 17 & 19 & 25 & 25 & 22 & 16 & 16 & 20 \\
\hline
\end{tabular}

Age (months): age of each goat in months at the day of bone marrow puncture. Vol BM (in mL): volume bone marrow after removal of potential blood clots. \# Cells $14 \mathrm{~d}$ culture: total amount of cells after 14 days of culture. \# Cells on microcarriers: quantity of cells used for seeding on microcarriers. \# Carriers (in g): quantity of carriers. \# Cells $/ 0.09 \mathrm{~g}$ carrier: quantity of cells $/ 0.09 \mathrm{~g}$ carrier. Period on carriers (in days): period that cells were seeded on carriers in osteogenic differentiation medium before surgical implantation.

defect were pair-wise compared by the stratified Wilcoxon rank sum test using Bonferroni's multiple comparisons adjustment technique. The digital radiographic density assessments were analyzed by a mixed model with tibia as random effect and composite, time, position, and the interaction between composite and time as categorical fixed effects at the $5 \%$ global significance level.

Histological bone healing assessments were analyzed by a mixed model with tibia as random effect and composite, time, and the interaction between composite and time as categorical fixed effects at the $5 \%$ global significance level.

Pair-wise comparisons in the mixed model were based on Bonferroni's multiple comparisons adjustment technique.

\section{Results}

All of the graft materials were easily implanted into the tibial defects and were considered to be stable before wound closure. None of the goats expressed signs of pain or lameness during the study period. Except for transient, discrete subcutaneous fluid accumulation at the surgical incision in the left tibia of three animals 2-4 weeks after surgery, no other clinically visible adverse reactions were observed. These minor seromas were successfully treated in all cases by sterile puncture and pressure bandages for several days.

\section{Isolation and culture of BM-derived cells}

The quantitative values of each BM sample and their characteristics after culturing and seeding on microcarriers are represented in Table 1. A mean volume of $11.5 \pm 5.1 \mathrm{~mL}$ BM could be aspirated. A mean amount of $4.07 \pm 2.4 \times 10^{6}$ BM-derived mesenchymal stem cells (BMSCs) was retrieved after a culture period of 14 days. On average $1.70 \pm$ $0.3 \times 10^{6}$ cells were loaded on $0.09 \mathrm{~g}$ microcarriers for a mean period of $20.0 \pm 3.7$ days before implantation. The result of the BM punctures differed largely between the goats. There was no significant correlation between the age of the goats and the volume of retrieved BM (Pearson's correlation coefficient, $0.198 ; p=0.639$ ). No significant correlation could be
FIG. 1. Box plots representing the differences in assessments for radiographic density (dens), distribution of the periosteal reaction and callus formation (dis), size of the periosteal reaction and callus formation (peri), and the soft tissue reaction (soft) between the several defects on the radiographies. X-axis: differences between defects with 0 indicating control defect, and 1,2 , and 3 indicating composite nos. 1, 2, and 3, respectively. Y-axis: result of differences.

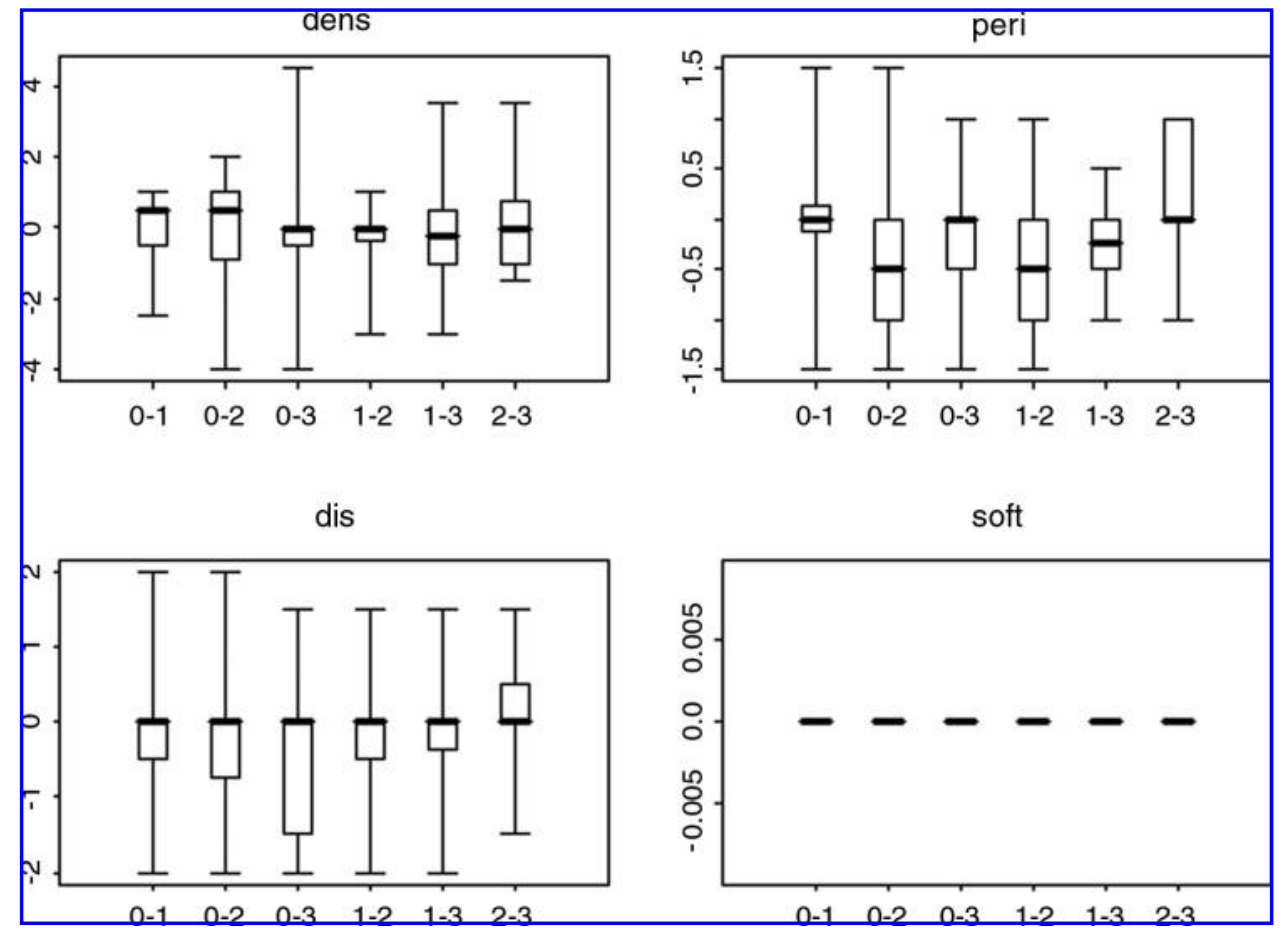




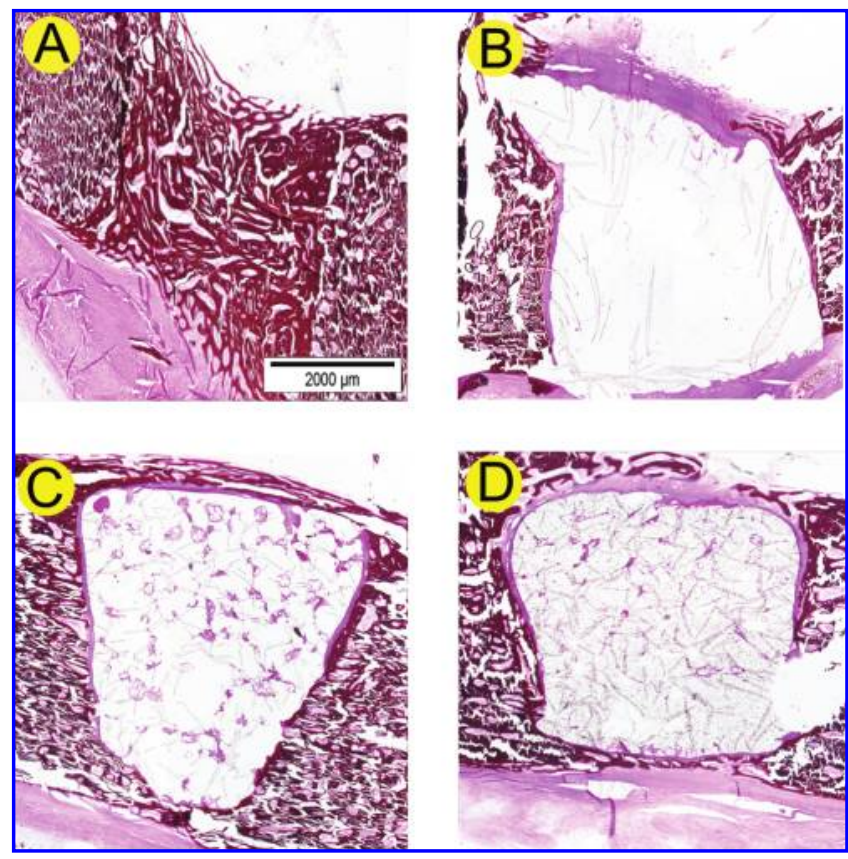

FIG. 2. Photomicrographs of tibial defects 8 weeks postsurgery in a goat (magnification $2 \times$, von Kossa staining). (A) The control defect is completely filled with bone. (B) Defect filled with composite no. 1. (C) Defect filled with composite no. 2: the composite is surrounded by a capsule of fibrous tissue; new bone formation is present around the fibrous capsule; several centers of tissue are present in the composite. (D) Defect filled with composite no. 3: several centers of tissue are present in the composite; the composite is surrounded by a capsule of fibrous tissue. Color images available online at www.liebertonline.com/ten.

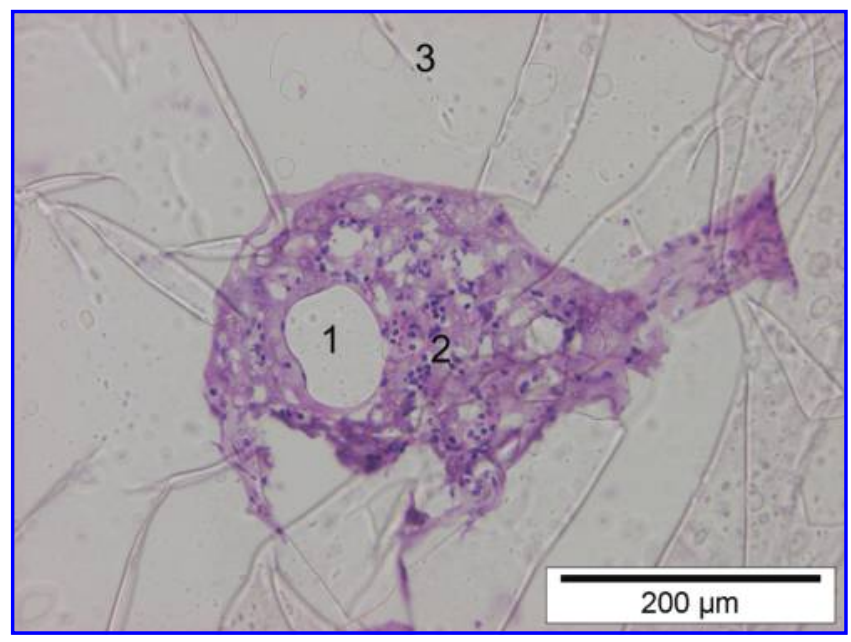

FIG. 3. Photomicrograph of a tibial defect treated with composite no. 2, 8 weeks after surgery (magnification 20x, H\&E staining). Several centers of tissue consisting of microcarriers (1), colonized and overgrowth by extracellular matrix, and viable cells (2) are present in the polymer (3). Color images available online at www.liebertonline.com/ten.

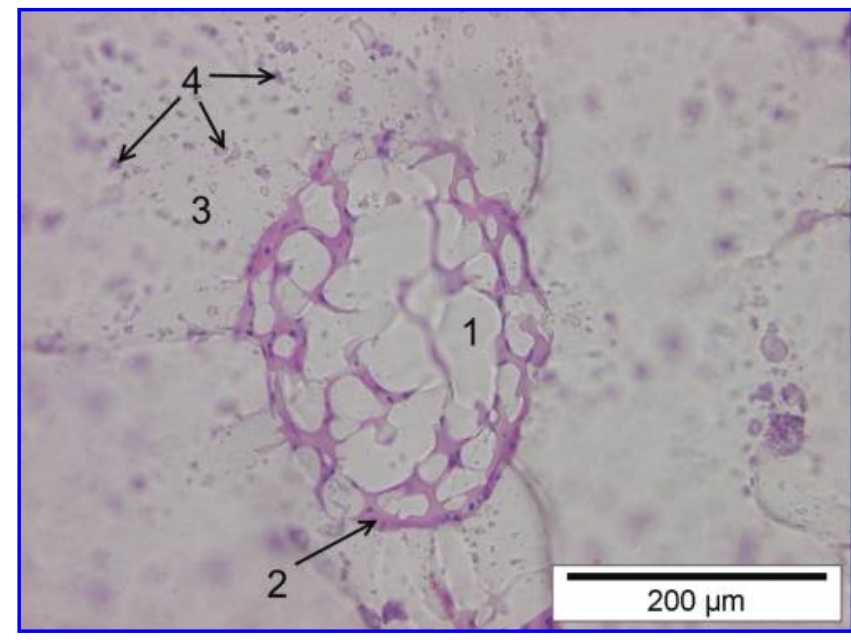

FIG. 4. Photomicrograph of a tibial defect treated with composite no. 3, 8 weeks after surgery (magnification 20x, $\mathrm{H} \& \mathrm{E}$ staining). Several centers of tissue consisting of microcarriers (1) colonized and overgrowth by extracellular matrix and viable cells (2) are present in the polymer. The polymer (3) contains diffusely spread granular material (4). Color images available online at www.liebertonline.com/ten.

demonstrated between the volume of BM and the number of cells cultivated after 14 days (Pearson's correlation coefficient, $-0.093 ; p=0.827$ ) or between the age of the goats and the amount of cells after 14 days of culture (Pearson's correlation coefficient, $-0.099 ; p=0.816$ ).

\section{Radiographic follow-up}

A significant difference between the composite-treated and the control defects was found for the distribution of the periosteal reaction and callus formation over time $(p=$ 0.0218), without significant pair-wise comparisons (Fig. 1). The size of the periosteal reaction and callus formation around each defect differed significantly between the composites ( $p=0.0215)$, with significant pair-wise comparisons between composite nos. 1 and $2(p=0.004)$. Composite no. 2 scored significantly higher than composite no. 1 concerning the size of the periosteal reaction and callus formation around each defect (Fig. 1). No significant differences were found with respect to the radiographic density of each defect over time and the soft tissue reaction (Fig. 1). This was in accordance with digitally measured gray-scale levels that revealed no differences between the defects $(p=0.81)$ and between the time periods $(p=0.39)$. The mean calculated gray-scale values for the complete study period of the control defect and the defects containing composite nos. 1, 2, and 3 were $73.8 \pm 2.3$, $75.8 \pm 2.1,74.4 \pm 2.2$, and $77.7 \pm 2.2$, respectively.

\section{Histological evaluation}

New bone formation was mostly pronounced in the control defects, originating at the intact cortex surrounding the defects and causing complete healing of the defect from 8 weeks after surgery (Fig. 2A). Control defects were filled with mesenchymal tissue at the center until complete bridging by bone tissue was achieved. Complete healing was not observed in the defects filled with the different 


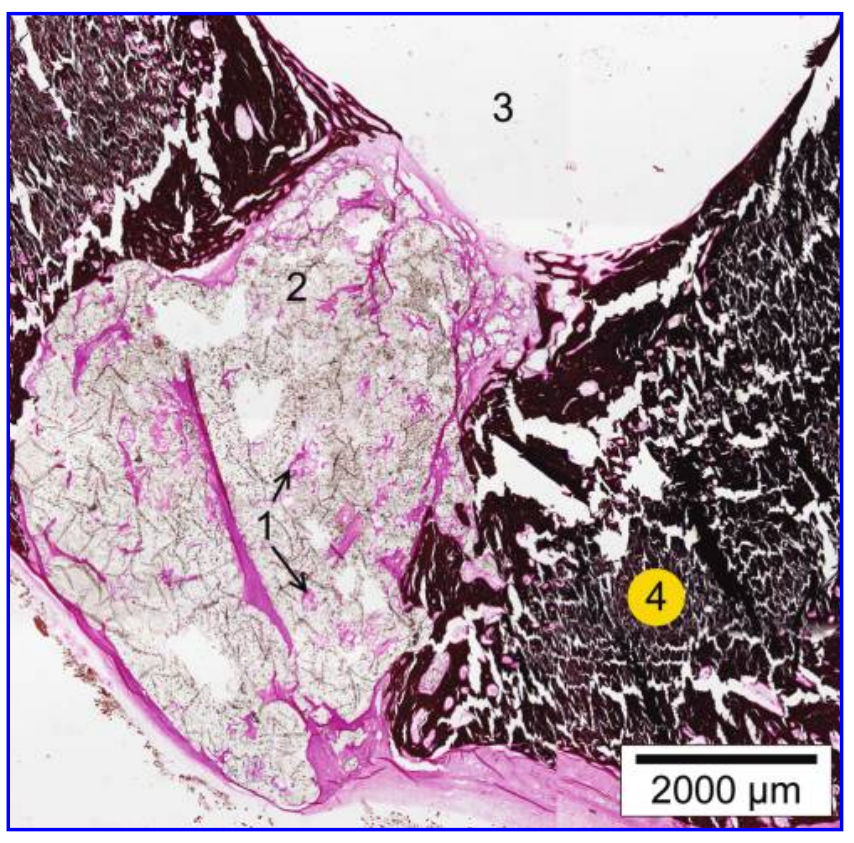

FIG. 5. Photomicrograph of a tibial defect treated with composite no. 3, 12 weeks after surgery (magnification $2 \times$, von Kossa staining). Several centers of tissue (1) are present in the composite. The composite is surrounded by a capsule of fibrous tissue. Several dots of von Kossa-positive tissue are present in the composite material (2), whereby newly formed trabecular bone (3) and a mature tibial cortex (4) can be noticed. Color images available online at www.liebertonline .com/ten.

composites during the study period. At 8 and 12 weeks postsurgery, composite-filled defects were characterized by the presence of fibrous tissue surrounding the centrally located polymer. New bone formation was present in the periphery of the defects. Polymer degradation was limited over time. Defects filled with composite nos. 2 and 3 were seen to contain several cellular tissue islands (Fig. 2C, D) consisting of microcarriers, connective tissue, and viable cells (Figs. 3 and 4). However, the volume of tissue surrounding the carriers in composite no. 3 was considered smaller than in polymer no. 2. Further, several nuclei incorporated into

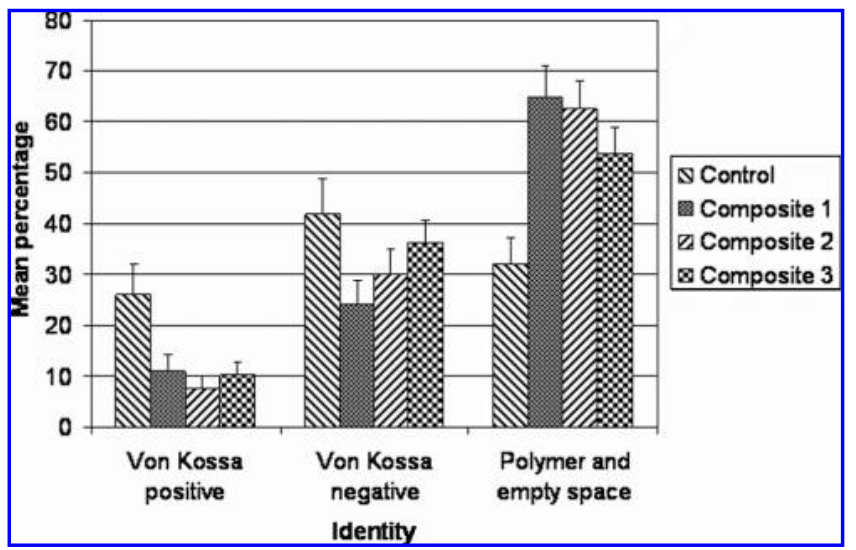

FIG. 6. Mean percentage (+ standard error of the mean) of each tibial defect for von Kossa-positive, von Kossanegative, and polymer and/or empty space.

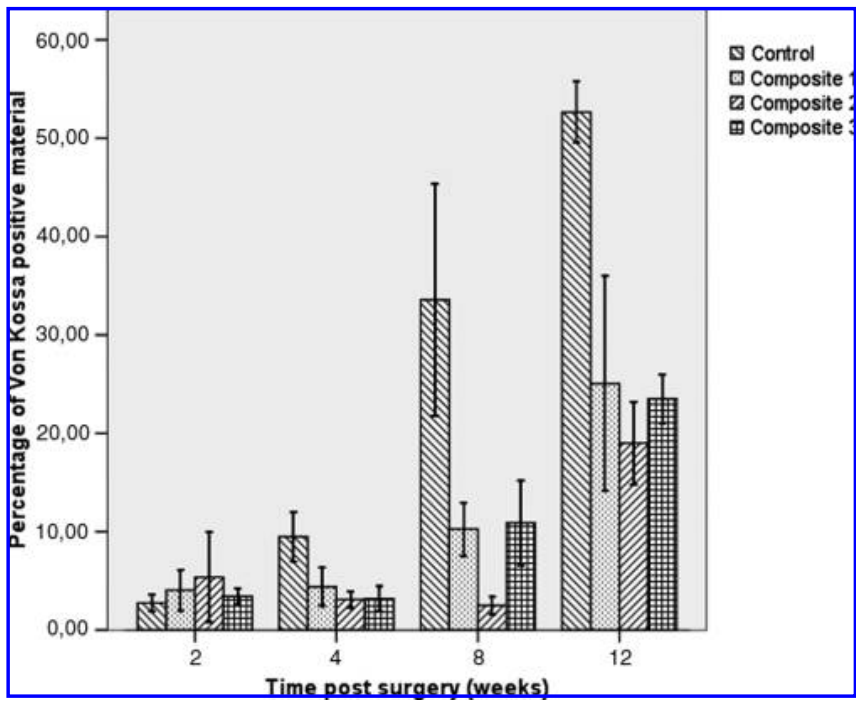

FIG. 7. Mean percentage ( \pm standard error of the mean) of von Kossa-positive material of the tibial defects filled with different composites in eight goats at 2, 4, 8, and 12 weeks postsurgery.

composite no. 3 appeared pyknotic. This composite contained also diffusely spread granular material that stained von Kossa positive and was subsequently identified as $\alpha$ TCP (Figs. 4 and 5). In 8 out of 64 tibial defects, clusters of high concentrations of cells were visible around the composite material.

\section{Histomorphometry}

The von Kossa-positive surface area was significantly influenced by the type of material $(p<0.0001)$, time $(p<0.0001)$, and the material-time interaction $(p=0.0208)$. Control defects contained significantly more von Kossapositive material (mean $26.1 \pm 6.0 \%$ ) than composite nos. 1 $(p=0.0025), 2(p=0.0001)$, and $3(p=0.0015)$ (mean values of $10.9 \pm 3.4 \%, 7.3 \pm 2.2 \%$, and $10.2 \pm 2.4 \%$, respectively) (Fig. $6)$. No differences were found for this parameter between the three composites. The percentage of von Kossa-positive staining increased significantly over time (Fig. 7).

The percentages of von Kossa-negative surface areas were significantly influenced by the type of material $(p=0.0093)$, time $(p=0.0031)$, and their interaction $(p=0.0116)$. Control defects $(41.8 \pm 7.0 \%)$ contained significantly $(p=0.035)$ more von Kossa-negative material than defects filled with composite no. $1(24.1 \pm 4.5 \%)$. The other composites did not differ significantly (mean of composite nos. 2 and 3: $29.9 \pm 5.1$ and $36.1 \pm 4.5 \%$, respectively) (Fig. 6). The percentage of von Kossa-negative staining decreased significantly over time (Fig. 8).

The percentages of surface area containing colorless material were significantly $(p<0.0001)$ influenced by the type of material, but not by time $(p=0.1479)$ and their interaction $(p=0.4501)$. Control defects contained significantly less colorless material (mean $32.1 \pm 5.2 \%$ ) than composite nos. 1 $(p=0.0001), 2(p=0.0004)$, and $3(p=0.0146)$ (mean values of $64.9 \pm 6.0 \%, 62.4 \pm 5.7 \%$, and $53.6 \pm 5.1 \%$, respectively). No differences were found between the three composites (Fig. 9). 


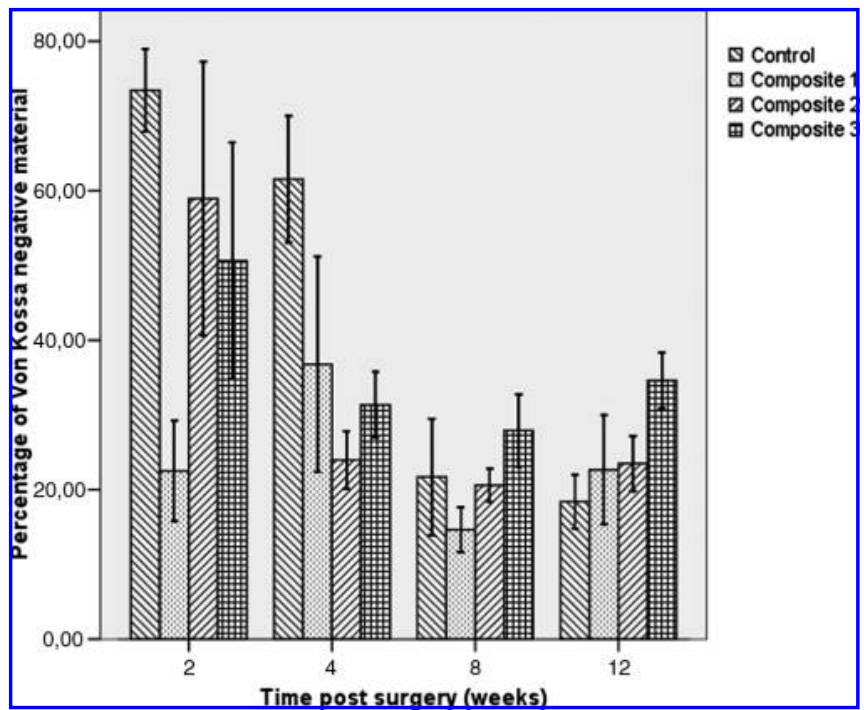

FIG. 8. Mean percentage ( \pm standard error of the mean) of von Kossa-negative material of the tibial defects filled with different composites in eight goats at 2, 4, 8, and 12 weeks postsurgery.

\section{Immunohistochemistry}

The CD3 activity examined by immunohistochemical analysis was negative in all samples except in three samples from one single goat with a few CD3-positive staining cells diffusely spread around the implanted composite. Bone tissue and granular material in defects filled with composite no. 3 stained metachromatically.

Immunohistochemical staining for MAC387 (macrophages) revealed no positive cells or tissue in the defects at any time. Bone tissue and the granular material in composite no. 3 stained metachromatically.

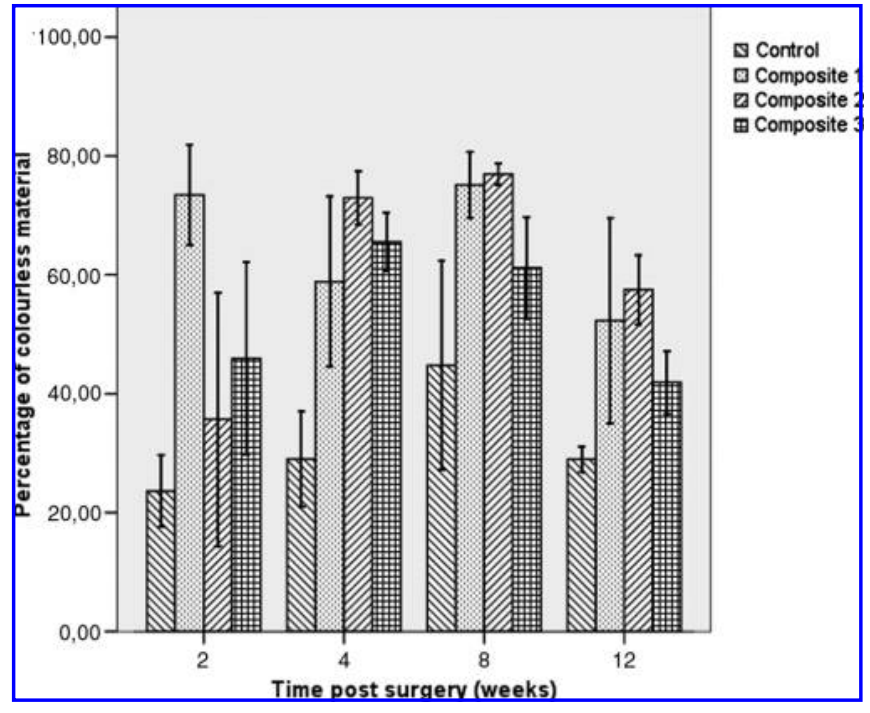

FIG. 9. Mean percentage ( \pm standard error of the mean) of colorless material of the tibial defects filled with different composites in eight goats at 2, 4, 8, and 12 weeks postsurgery.

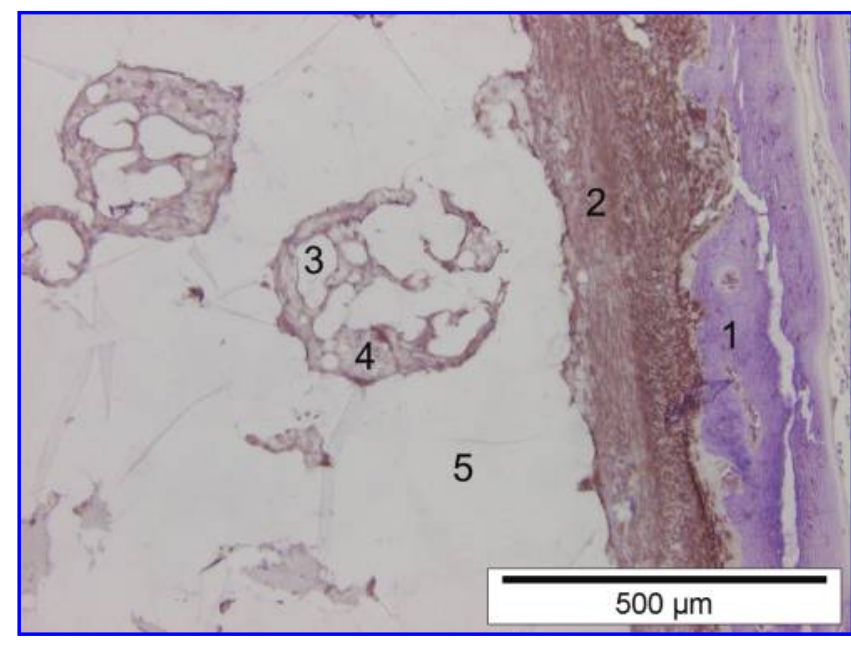

FIG. 10. Photomicrograph of a tibial defect treated with composite no. 2, which stained immunohistochemically for vimentin 12 weeks after surgery. The capsule of tissue around the polymer and the tissue centers in the polymer are positively stained (magnification $\times 10$ ). 1 , Newly formed bone (metachromatic staining); 2, capsule of tissue around composite (vimentin positive); 3 , microcarrier; 4 , tissue and cells around the microcarrier (vimentin positive); 5, polymer. Color images available online at www.liebertonline.com/ten.

Intensive positive staining for vimentin (mesenchymal tissue) was observed in the tissue concentrations in composite nos. 2 and 3, the connective tissue surrounding the composites, and the fibrous tissue inside the cortical bone tissue (Figs. 10 and 11). Bone tissue and the granular material in composite no. 3 stained metachromatically.

Immunohistochemical staining for osteocalcin revealed a slightly positive staining of tissues in and around the microcarriers in composite nos. 2 and 3, the connective tissue surrounding the different composites, and the tissue inside the newly formed trabecular bone (Figs. 12 and 13).

\section{Discussion}

In the present study, the biological behavior of porous bone scaffolds prepared from methacrylate-endcapped poly(D,L-lactide-co- $\varepsilon$-caprolactone) mixed with BMSCs was studied in a tibial cortical defect goat model. Critical-sized defects were not used for this study to facilitate the surgical procedures during these initial basic steps in the study. They should, however, be a logical sequel for further experiments. Although BMSCs survived and showed signs of new bone formation as stated in the first part of the research hypothesis, bone healing was still in its initial stages in the polymer composites at the end of the study period compared to control defects where complete healing was present.

Bone tissue engineering has been shown to be an effective approach for bone regeneration, and BMSCs have proved to be a major cell source during the bone engineering process. The osteogenic potential of BMSCs has been demonstrated extensively both in vitro and in vivo, and many studies have succeeded in repairing bone defects using BMSCs in different animal models. ${ }^{12-21}$ Not only can osteogenically induced BMSCs provide a source for new bone formation, but the 


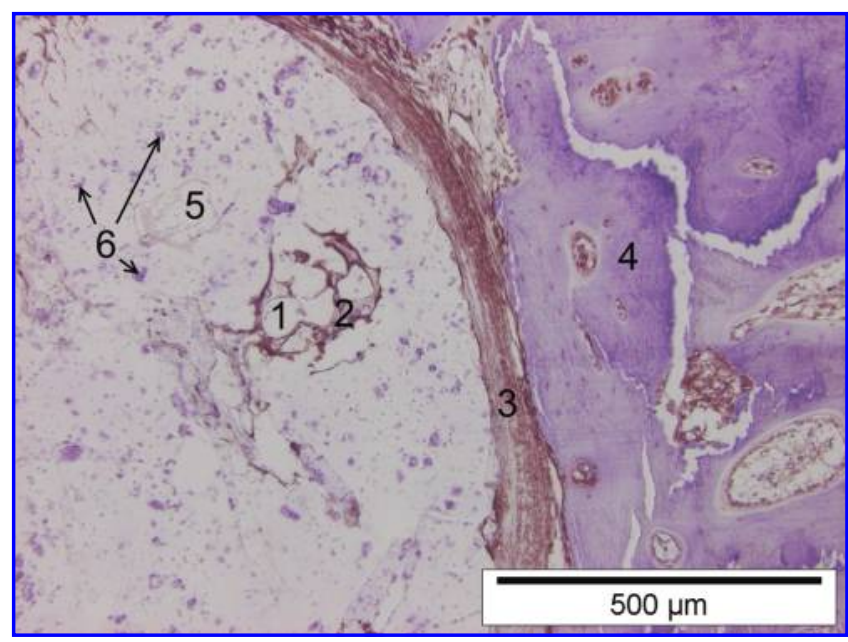

FIG. 11. Photomicrograph of a tibial defect treated with composite no. 3, which stained immunohistochemically for vimentin 8 weeks after surgery. The tissue between the newly formed metachromatic staining bone, the capsule of tissue around the polymer, and the tissue centers in the polymer are positively stained (magnification $\times 10$ ). 1, Microcarrier; 2 , tissue and cells around the microcarrier (vimentin positive); 3 , capsule of tissue around composite (vimentin positive); 4, newly formed bone (metachromatic staining); 5, polymer; 6, granular material in polymer (metachromatic staining). Color images available online at www.liebertonline.com/ten.

transformed cells can also secrete important growth factors regulating further bone healing.

The present study found no age-related influence on the number of cultured BMSCs derived from BM punctures in goats. Kotobuki et al. demonstrated that BMSCs could even proliferate from aged marrow cells (viability greater than

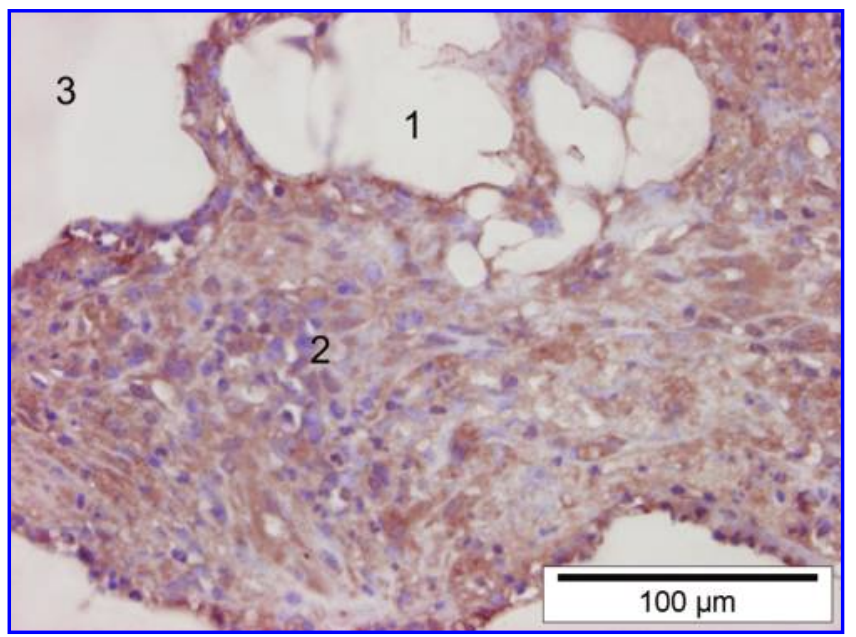

FIG. 12. Photomicrograph of a center of tissue in tibial defect treated with composite no. 2, which stained immunohistochemically for osteocalcin 12 weeks after surgery. There is a slightly positive staining of the tissue, and the nuclei are staining negative (magnification $\times 40$ ). 1 , Microcarrier; 2 , tissue and cells around the microcarrier (slightly positive); 3, polymer. Color images available online at www.liebertonline.com/ten.

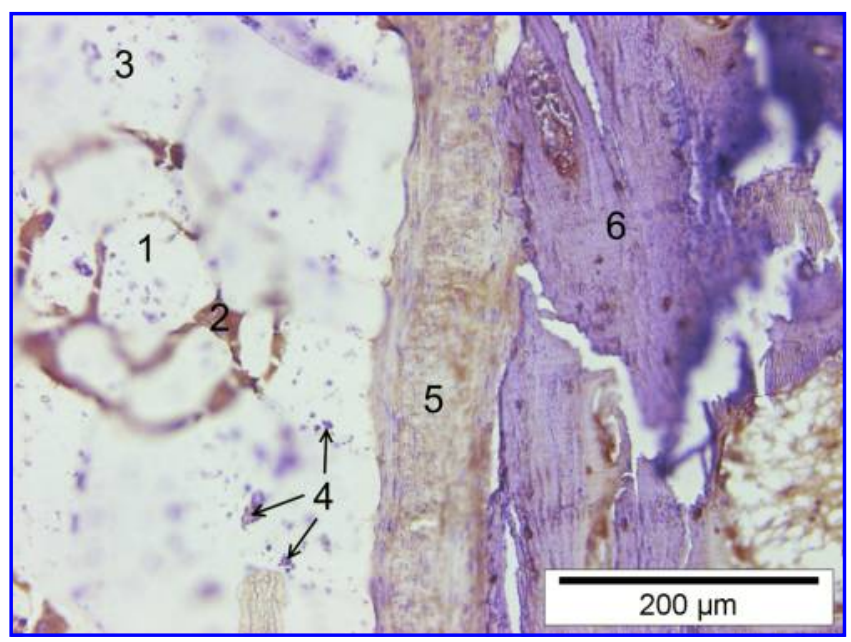

FIG. 13. Photomicrograph of a tibial defect treated with composite no. 3, which stained immunohistochemically for osteocalcin 8 weeks after surgery. There is a slightly positive staining of the tissue around the microcarriers, the capsule around the polymer, and the tissue between the newly formed metachromatically stained trabecular bone. The nuclei are staining negative (magnification $\times 20$ ). 1 , Microcarrier; 2 , tissue and cells around the microcarrier (slightly osteocalcin positive); 3 , polymer; 4 , granular material in polymer (metachromatic staining); 5, capsule of tissue around composite (slightly osteocalcin positive); 6 , newly formed bone (metachromatic staining). Color images available online at www.liebertonline.com/ten.

$90 \%) .^{22}$ This might suggest that not only young but also geriatric patients might be treated with autologous BMSCs or osteoblasts derived from BM. Bone reconstruction procedures are frequently performed in the older individuals, for example, in oral surgery, to allow stable placement of dental implants in an augmented bone area. ${ }^{23}$ Also bone reconstruction after tumor resection is challenging in the elderly patient. ${ }^{24}$

Photopolymerizing materials used for bone reconstruction have promising characteristics: these products can be injected into a bone defect in moldable form and solidified in situ by exposure to a specific light source, maintaining the form and shape of the implant. ${ }^{25-31}$ In the present study, photopolymerizable scaffolds based on D,L-lactide and $\varepsilon$ caprolactone to encapsulate BMSC-loaded microcarriers were used in an experimental model for bone regeneration. Declercq et al. demonstrated in a previous in vitro study that the encapsulated cells did not show pyknotic nuclei, pointing out that the photopolymerization and handling of the viscous polymer/microcarrier paste were not detrimental for the survival of the cells. ${ }^{9}$ The present study confirmed these results in an in vivo setting and demonstrated the implanted cells' ability to proliferate and produce a calcified matrix (osteocalcin positive) inside the polymer as cell proliferation and matrix production were absent in the polymer composite without BMSCs.

Although radiographic evaluation did not reveal major differences between the control defects and the three different composites, the control defects had the tendency to become more dense 6 weeks after surgery than defects filled with composites. However, the lowest overall mean gray-scale values were observed in the control defect followed by com- 
posite nos. 2, 1, and 3, respectively (not significantly different). This finding is in contrast with those of a previous study ${ }^{7}$ in which the controls showed the highest radiographic density. Bone healing was evaluated radiographically using a fixed time interval. Small but significant differences were found only for the occurrence of the periosteal reactions and callus formation, but not for radiographic density and soft tissue reactions. This was also in contrast with the previous study, where more radiographic findings were significantly present. ${ }^{7}$ A possible explanation for the differences between each study might be that in the present study, the radiographic evaluation was done over a 12-week period after surgery compared to a 32-week follow-up in the previous study. Major differences between composites were seen from 8-week postsurgery in both studies. Not surprisingly, standard radiographic techniques had a low sensitivity to detect significant changes in the early phases of bone healing.

Von Kossa-positive material is indicative for the presence of phosphate and carbonate, the anions that bind calcium in tissues. On the bone sections in the present study, the von Kossa-positive material corresponded with the presence of either the mineralized bone or the $\alpha$-TCP particles that were included in composite no. 3 (Fig. 5). On the other hand, von Kossa-negative staining mainly refers to the presence of pure fibrous tissue, whereas colorless zones are indicative for the presence of the pure polymer or possible artefacts.

Overall, the empty control defects healed very fast. The results of the present study demonstrated insufficient osteoconductive properties of the used composites that were characterized by the presence of fibrous tissue surrounding the implant material. This was in contrast with the results of the previous study, ${ }^{7}$ where bone ingrowth at the periphery of the composite material was seen even at early stages. A possible explanation for this lack of bone ingrowth in the present study might be the lower porosity of the polymer compared to the previous study because no porogen was used in the present study as the addition of gelatine as a porogen seemed to have a negative influence on in vitro cell viability. ${ }^{8}$ The present study identified several tissue clusters in the composites originating from the seeded BMSCs as tissue clusters were absent in the polymer composite without BMSCs. This underlines the cells' potential to proliferate and further differentiate in an osteogenic direction. Survival and proliferation of the cells are only possible when the polymer has an adequate porosity. No extra porogen was included in the composition of the scaffolds. Preceding experiments showed that porosity could be induced by the leaching of the plastizer and as a result of the degradation of the polyester and the CultiSpher microcarrier particles. Further, during the mixing of the viscous crosslinkable polyester and the cell-seeded microcarriers, air bubbles were trapped and contributed as macroporous pockets. Preceding in vitro experiments with cells grown on microcarriers and immobilized in the crosslinkable polyester proved to maintain an acceptable viability. Further, triacetin has a very low molecular weight and is washed out fast, generating some more micropores. The observed degree of proliferation of the BMSCs was considered rather limited. A higher porosity of the polymers would most likely have allowed a more pronounced proliferation activity. It was surprising to observe that $\alpha$-TCP-supplemented polymers demonstrated less BMSC proliferation characterized by less amounts of tissue and cells found around the microcarriers. Although $\alpha$-TCP is most likely not toxic for the cells, this calcium phosphate has been reported to be inferior with regard to seeding efficacy, increase in osteogenic marker genes, and three-dimensional cell alignment compared to other bone grafts like mineralized collagen. ${ }^{32}$ The addition of $\alpha$-TCP might also decrease the overall porosity of the polymer, thus possibly interfering with proliferation potential.

The presence of clusters of cells around the composites in a single goat might be indicative for the occurrence of an inflammatory response because a small number of these cells were identified as T-lymphocytes. This might have been induced by the presence of the slowly degrading polymers, although no adverse reactions were recorded in previous studies $^{7,8}$ and no clinical signs of inflammatory reactions (lameness; swelling, redness, and hyperthermia at the operated legs) were observed during the study period in the other goats. A more obvious explanation might be that these findings represented a reaction against a possible contamination during surgery.

Histomorphometrical evaluation confirmed a slower bone healing and remodeling in bone defects containing composites in comparison with control defects, although no differences were found between the three composites. The absence of ingrowth of new bone into the polymer composites reflects the limited osteoconductive properties of the polymers.

Similar to the previous study in goats without the addition of BMSCs, ${ }^{7}$ polymer degradation failed to become visible during the first 12 weeks postsurgery. The present study accentuates the need for further physicochemical adaptations of the polymers used to improve their osteoconductive properties. More recently, hydrogels seeded with bone-forming cells have been reported as promising alternative scaffolds for bone regeneration purposes. ${ }^{3,12,33-40}$ These substances can also be crosslinked by photopolymerization. ${ }^{41,42}$

The BMSCs in the present study have been cultivated in an osteogenic medium to stimulate their differentiation to bone-forming cells. A clearly bone-forming potential was encountered in the composite-seeded cells (Fig. 12), proving the osteogenic capacity of the BMSCs in the used polymer.

In a previous study, ${ }^{11}$ metachromatic staining was also observed, which was suggestive for the presence of mature bone. Most likely, all calcified tissues will have a metachromatic staining after immunohistochemical staining with the techniques of the present protocol. The metachromatic granular material in composite no. 3 was identified as $\alpha$-TCP particles using the standard light microscopic techniques.

The second part of our research hypothesis, in which we anticipated an improvement in bone healing characteristics of the treated cortical defects compared to earlier reported results, ${ }^{7}$ is not true due to a too low resorption and porosity of the polymers impeding BMSCs' proliferation and bone ingrowth.

\section{Conclusion}

The use of osteogenic differentiated BMSCs is promising in the process of bone tissue engineering and has been reported in different animal models. ${ }^{12-21}$ Despite their excellent biocompatibility, the osteoconductive characteristics of the in situ crosslinkable methacrylate-endcapped poly-(D, 
L-lactide-co- $\varepsilon$-caprolactone) combined with BMSCs were limited in the first weeks after implantation. The addition of $\alpha$-TCP seemed to have a less positive effect on expansion and growth of the BMSCs than other polymer composites. A faster resorption and higher porosity of the polymer seems imperative to promote BMSCs' proliferation and encourage bone ingrowth from the surrounding tissues. Further biochemical adaptation of the present polymer is mandatory to improve its bone grafting properties. Their in situ crosslinkable characteristic in combination with osteogenic differentiated BMSCs offers potentials for the restoration of complex orthopedic situations.

\section{Acknowledgments}

The authors thank Cindy De Baere, Sarah Loomans, Bart De Pauw, and Leen Pieters for their excellent technical assistance.

\section{Disclosure Statement}

No competing financial interests exist.

\section{References}

1. Damien, C.J., and Parsons, J.R. Bone graft and bone graft substitutes: a review of current technology and applications. J Appl Biomater 2, 187, 1991.

2. Kakaiya, R., Miller, W.V., and Gudino, M.D. Tissue transplant-transmitted infections. Transfusion 31, 277, 1991.

3. Bianco, P., and Robey, P.G. Stem cells in tissue engineering. Nature 414, 118, 2001.

4. Jiang, Y., Jahagirdar, B.N., Reinhardt, R.L., Schwartz, R.E., Keene, C.D., Ortiz-Gonzalez, X.R., Reyes, M., Lenvik, T., Lund, T., Blackstad, M., Du, J., Aldrich, S., Lisberg, A., Low, W.C., Largaespada, D.A., and Verfaillie, C.M. Pluripotency of mesenchymal stem cells derived from adult marrow. Nature 418, 41, 2002.

5. Murphy, J.M., Dixon, K., Beck, S., Fabian, D., Feldman, A., and Barry, F. Reduced chondrogenic and adipogenic activity of mesenchymal stem cells from patients with advanced osteoarthritis. Arthritis Rheum 46, 704, 2002.

6. Thomson, R., Shung, A., Yaszemski, M., and Mikos, A. Polymer scaffold processing. In: Lanza, R., Langer, R., and Vacanti, J., eds. Principles of Tissue Engineering. San Diego, CA: Academic Press, 2000, pp. 251-262.

7. Vertenten, G., Vlaminck, L., Gorski, T., Schreurs, E., van den Broeck, W., Duchateau, L., Schacht, E., and Gasthuys, F. Evaluation of an injectable, photopolymerizable threedimensional scaffold based on D,L-lactide and epsiloncaprolactone in a tibial goat model. J Mater Sci Mater Med 19, 2761, 2008.

8. Tielens, S., Declercq, H., Gorski, T., Lippens, E., Schacht, E., and Cornelissen, M. Gelatin-based microcarriers as embryonic stem cell delivery system in bone tissue engineering: an in-vitro study. Biomacromolecules 8, 825, 2007.

9. Declercq, H.A., Gorski, T.L., Tielens, S.P., Schacht, E.H., and Cornelissen, M.J. Encapsulation of osteoblast seeded microcarriers into injectable, photopolymerizable threedimensional scaffolds based on D,L-lactide and epsiloncaprolactone. Biomacromolecules 6, 1608, 2005.

10. Dorea, H.C., McLaughlin, R.M., Cantwell, H.D., Read, R., Armbrust, L., Pool, R., Roush, J.K., and Boyle, C. Evaluation of healing in feline femoral defects filled with cancellous autograft, cancellous allograft or bioglass. Vet Comp Orthop 18, 157, 2005.

11. Vertenten, G., Vlaminck, L., Ducatelle, R., Lippens, E., Cornelissen, M., and Gasthuys, F. Immunohistochemical analysis of low-temperature methylmethacrylate resin embedded goat tissues. Anat Histol Embryol 2008. Accepted for publication .

12. Arinzeh, T.L., Peter, S.J., Archambault, M.P., van den Bos, C., Gordon, S., Kraus, K., Smith, A., and Kadiyala, S. Allogeneic mesenchymal stem cells regenerate bone in a criticalsized canine segmental defect. J Bone Joint Surg Am 85A, 1927, 2003.

13. Bruder, S.P., Kraus, K.H., Goldberg, V.M., and Kadiyala, S. The effect of implants loaded with autologous mesenchymal stem cells on the healing of canine segmental bone defects. J Bone Joint Surg Am 80A, 985, 1998.

14. Dai, K.R., Xu, X.L., Tang, T.T., Zhu, Z.A., Yu, C.F., Lou, J.R., and Zhang, X.L. Repairing of goat tibial bone defects with BMP-2 gene-modified tissue-engineered bone. Calcified Tissue Int 77, 55, 2005.

15. Kon, E., Muraglia, A., Corsi, A., Bianco, P., Marcacci, M., Martin, I., Boyde, A., Ruspantini, I., Chistolini, P., Rocca, M., Giardino, R., Cancedda, R., and Quarto, R. Autologous bone marrow stromal cells loaded onto porous hydroxyapatite ceramic accelerate bone repair in critical-size defects of sheep long bones. J Biomed Mater Res 49, 328, 2000.

16. Maniatopoulos, C., Sodek, J., and Melcher, A.H. Bone formation in vitro by stromal cells obtained from bone marrow of young adult rats. Cell Tissue Res 254, 317, 1988.

17. Muraglia, A., Martin, I., Cancedda, R., and Quarto, R. A nude mouse model for human bone formation in unloaded conditions. Bone 22, 131S, 1998.

18. Petite, H., Viateau, V., Bensaid, W., Meunier, A., de Pollak, C., Bourguignon, M., Oudina, K., Sedel, L., and Guillemin, G. Tissue-engineered bone regeneration. Nat Biotechnol 18, 959, 2000.

19. Shang, Q.X., Wang, Z., Liu, W., Shi, Y.H., Cui, L., and Cao, Y.L. Tissue-engineered bone repair of sheep cranial defects with autologous bone marrow stromal cells. I Craniofac Surg 12, 586, 2001.

20. Yuan, J., Cui, L., Zhang, W.J., Liu, W., and Cao, Y. Repair of canine mandibular bone defects with bone marrow stromal cells and porous beta-tricalcium phosphate. Biomaterials 28, 1005, 2007.

21. Zhu, L., Liu, W., Cui, L., and Cao, Y.L. Tissue-engineered bone repair of goat femur defects with osteogenically induced bone marrow stromal cells. Tissue Eng 12, 423, 2006.

22. Kotobuki, N., Hirose, M., Takakura, Y., and Ohgushi, H. Cultured autologous human cells for hard tissue regeneration: preparation and characterization of mesenchymal stem cells from bone marrow. Artif Organs 28, 33, 2004.

23. Wang, H.L., and Boyapati, L. "PASS" principles for predictable bone regeneration. Implant Dent 15, 8, 2006.

24. Marx, R.E. Platelet-rich plasma: evidence to support its use. J Oral Maxillofac Surg 62, 489, 2004.

25. Sharma, B., Williams, C.G., Khan, M., Manson, P., and Elisseeff, J.H. In vivo chondrogenesis of mesenchymal stem cells in a photopolymerized hydrogel. Plast Reconstr Surg 119, 112, 2007.

26. Burdick, J.A., Frankel, D., Dernell, W.S., and Anseth, K.S. An initial investigation of photocurable three-dimensional lactic acid based scaffolds in a critical-sized cranial defect. Biomaterials 24, 1613, 2003. 
27. Burdick, J.A., Padera, R.F., Huang, J.V., and Anseth, K.S. An investigation of the cytotoxicity and histocompatibility of in situ forming lactic acid based orthopedic biomaterials. J Biomed Mater Res 63, 484, 2002.

28. Grijpma, D.W., Hou, Q.P., and Feijen, J. Preparation of biodegradable networks by photo-crosslinking lactide, epsilon-caprolactone and trimethylene carbonate-based oligomers functionalized with fumaric acid monoethyl ester. Biomaterials 26, 2795, 2005.

29. Ifkovits, J.L., and Burdick, J.A. Review: photopolymerizable and degradable biomaterials for tissue engineering applications. Tissue Eng 13, 2369, 2007.

30. Storey, R.F., Warren, S.C., Allison, C.J., Wiggins, J.S., and Puckett, A.D. Synthesis of bioabsorbable networks from methacrylate-endcapped polyesters. Polymer 34, 4365, 1993.

31. Temenoff, J.S., and Mikos, A.G. Injectable biodegradable materials for orthopedic tissue engineering. Biomaterials 21, 2405, 2000.

32. Niemeyer, P., Krause, U., Fellenberg, J., Kasten, P., Seckinger, A., Ho, A.D., and Simank, H.G. Evaluation of mineralized collagen and alpha-tricalcium phosphate as scaffolds for tissue engineering of bone using human mesenchymal stem cells. Cells Tissues Organs 177, 68, 2004.

33. Bianco, P., and Robey, P.G. Marrow stromal stem cells. I Clin Invest 105, 1663, 2000.

34. Endres, M., Hutmacher, D.W., Salgado, A.J., Kaps, C., Ringe, J., Reis, R.L., Sittinger, M., Brandwood, A., and Schantz, J.T. Osteogenic induction of human bone marrow-derived mesenchymal progenitor cells in novel synthetic polymerhydrogel matrices. Tissue Eng 9, 689, 2003.

35. Srouji, S., Kizhner, T., and Livne, E. 3D scaffolds for bone marrow stem cell support in bone repair. Regen Med 1, 519, 2006.

36. Srouji, S., and Livne, E. Bone marrow stem cells and biological scaffold for bone repair in aging and disease. Mech Ageing Dev 126, 281, 2005.

37. Srouji, S., Maurice, S., and Livne, E. Microscopy analysis of bone marrow-derived osteoprogenitor cells cultured on hydrogel 3-D scaffold. Microsc Res Tech 66, 132, 2005.
38. Trojani, C., Boukhechba, F., Scimeca, J.C., Vandenbos, F., Michiels, J.F., Daculsi, G., Boileau, P., Weiss, P., Carle, G.F., and Rochet, N. Ectopic bone formation using an injectable biphasic calcium phosphate/Si-HPMC hydrogel composite loaded with undifferentiated bone marrow stromal cells. Biomaterials 27, 3256, 2006.

39. Tsuchida, H., Hashimoto, J., Crawford, E., Manske, P., and Lou, J. Engineered allogeneic mesenchymal stem cells repair femoral segmental defect in rats. JOrthop Res 21, 44, 2003.

40. Vehof, J.W., Fisher, J.P., Dean, D., van der Waerden, J.P., Spauwen, P.H., Mikos, A.G., and Jansen, J.A. Bone formation in transforming growth factor beta-1-coated porous poly(propylene fumarate) scaffolds. J Biomed Mater Res 60, 241, 2002.

41. Buxton, A.N., Zhu, J., Marchant, R., West, J.L., Yoo, J.U., and Johnstone, B. Design and characterization of poly(ethylene glycol) photopolymerizable semi-interpenetrating networks for chondrogenesis of human mesenchymal stem cells. Tissue Eng 13, 2549, 2007.

42. Li, Q., Wang, J., Shahani, S., Sun, D.D., Sharma, B., Elisseeff, J.H., and Leong, K.W. Biodegradable and photocrosslinkable polyphosphoester hydrogel. Biomaterials 27, 1027, 2006.

Address correspondence to: Geert Vertenten, D.V.M. Department of Surgery and Anaesthesiology of Domestic Animals Faculty of Veterinary Medicine Ghent University

Salisburylaan 133 Merelbeke 9820

Belgium

E-mail: geert.vertenten@ugent.be

Received: July 2, 2008

Accepted: October 1, 2008

Online Publication Date: December 8, 2008 



\section{This article has been cited by:}

1. Tracey Baas. 2012. Rebuilding a better bone. Science-Business eXchange 5:8. . [CrossRef]

2. Min Guan, Wei Yao, Ruiwu Liu, Kit S Lam, Jan Nolta, Junjing Jia, Brian Panganiban, Liping Meng, Ping Zhou, Mohammad Shahnazari, Robert O Ritchie, Nancy E Lane. 2012. Directing mesenchymal stem cells to bone to augment bone formation and increase bone mass. Nature Medicine 18:3, 456-462. [CrossRef]

3. Evi Lippens, Geert Vertenten, Jordi Gironès, Heidi Declercq, Jimmy Saunders , Jan Luyten , Luc Duchateau , Etienne Schacht, Lieven Vlaminck, Frank Gasthuys , Maria Cornelissen . 2010. Evaluation of Bone Regeneration with an Injectable, In Situ Polymerizable Pluronic $®$ F127 Hydrogel Derivative Combined with Autologous Mesenchymal Stem Cells in a Goat Tibia Defect Model. Tissue Engineering Part A 16:2, 617-627. [Abstract] [Full Text HTML] [Full Text PDF] [Full Text PDF with Links] 